\title{
Humanities in medicine: experience at Pondicherry Institute of Medical Sciences, India
}

\section{MANJIRI PHANSALKAR, THOMAS ALEXANDER, SUSAN SOLOMON, RENU G'BOY VARGHESE}

\begin{abstract}
A few institutes in India have started a programme of Humanities in Medicine (HiM) on a small scale. In 2014, the Pondicherry Institute of Medical Sciences (PIMS) decided to begin an HiM programme for undergraduate students and this has been conducted successfully for the last three years. The major strengths of the programme have been its formal integration within the curriculum and the contributions of a large number of enthusiastic, talented and motivated faculty. In this report, we wish to trace the evolution and implementation of the HiM programme in our institution.
\end{abstract}

\section{Introduction}

The Medical Education Unit and the administrative authorities of the Pondicherry Institute of Medical Sciences felt there was a need to inculcate in medical students a love for the art of healing, ethical and humanitarian medicine. Hence, it was decided to introduce a programme of "Humanities in Medicine". The key challenge was to understand the term "Humanities in Medicine" (HiM) as "Humanities" is often confused with "humanity". The Oxford English Dictionary defines the word humanities as "learning concerned with human culture, especially literature, history, art, music and philosophy" (1). According to the same dictionary, humanity however means different things: (a) human beings collectively (b) the state of being human and (c) the quality of being humane. Deborah Kirklin, an international authority on the subject, defines humanities in medicine as "An interdisciplinary endeavour that draws on the creative and intellectual strengths of diverse disciplines like literature, art, creative writing, drama, film, music, philosophy, anthropology and history in pursuit of medical educational goals" (2).

Authors: Manjiri Phansalkar (Manjipath@gmail.com) Department of Pathology, Pondicherry Institute of Medical Sciences, Kalapet, Pondicherry, 605014 INDIA; Thomas Alexander (Talex99@gmail.com),Consultant Gastroenterologist, Zulekha Hospital, Sharjah, United Arab Emirates; Susan Solomon (corresponding author - susanjsolomon@gmail.com), Department of Psychiatry, Pondicherry Institute of Medical Sciences, Kalapet, Pondicherry, 605014 INDIA ; Renu G'Boy Varghese (Renugboy@gmail.com), Pondicherry Institute of Medical Sciences, Kalapet, Pondicherry, 605014 INDIA

To cite: Phansalkar M, Alexander T, Solomon S, Varghese RG. Humanities in medicine: experience at Pondicherry Institute of Medical Sciences, India. Indian J Med Ethics. 2019 Jan-Mar;4(1)NS: 71-2.DOI:10.20529/ IJME.2018.052.

Published online on July 3, 2018.

(c) Indian Journal of Medical Ethics 2018

\section{Methodology}

A small team was formed, comprising the Dean (TA), Vice Dean (SS) of the Medical Education Unit and a coordinator (MP), for the overall conduct of the programme. The objective was to inculcate in students love for the art of healing, ethical and humanitarian medicine. The team was of the firm opinion that every medical student needs to experience this training. It was therefore decided to include the entire class, with attendance being marked, and to conduct the sessions during the regular teaching hours. Hence, it was decided to integrate HiM into the curriculum for the $1^{\text {st }}, 2^{\text {nd }}$ and pre-final year students during Semester II, Semester IV and Semester VI, from January to May of every year. Forty hours which were additional tutorial hours were dedicated to this endeavour. Regarding the selection of topics, we invited suggestions from faculty and students, and acquired many ideas from the ATCOM (Attitudes \& Communication) module, introduced by the Medical Council of India (3).

We decided that the sessions would be conducted altogether differently from the routine didactic classes. Certain guidelines were decided, such as: - each session would be conducted by multiple faculty members so that various viewpoints would be expressed on sensitive issues, philosophical and ethical matters, attitudes, communication skills, etc. The coordinator chose a team of facilitators across specialties for each topic, keeping in mind their interests, experience and ability to deal with the given topic. The coordinator decided to attend every session in order to identify the interests and participation of students and faculty and to make modifications in further sessions, if needed.

\section{Implementation}

The HiM programme was formally commenced in January 2015. Every week, one/two-hour sessions were started for all three semesters, simultaneously. Thus, three different topics were conducted each week. Commonly used methodologies were role play, debates, performing arts, interviews, appreciation of paintings, panel discussions, video clips, films, narrations, games, group activities, creative writing and reflective writing. For a few sessions, we also invited guest faculty, including those from a non-medical background.

To give an example, a session on 'Perspectives on happiness' was conducted for semester II students. In the beginning of the session, three questions were put before the students for 
reflection...

1. What will make me happy now?

2. What will make me happy after 5 years?

3. What will make me happy after 50 years?

Written answer slips were collected to elicit students' perspectives on the topic (this also served as a means to document attendance). Following this, a balloon game was played by the students, with the help of which, various perspectives on happiness were explored through studentfacilitator interaction. In the last 15 minutes, a TED-talk video on the same topic was shown and the session was concluded within one hour.

Topics for the sessions are decided semester-wise. We have now reached a stage with more topics than the available hours! Overall these topics can be categorised as (a) human values (b) medical ethics (c) communication skills (d) philosophy and (e) history of medicine. Topics for these sessions included "Right or wrong," "Art and science of death disclosure", "Who am I?", "We are being watched", "Curiosity about the human body" etc. Clinicians shared their experiences on themes like "A rewarding day in my life" and "My privileges and commitments as a doctor".

\section{Challenges and gains}

The HiM programme was started in 2015 with the objective of inculcating ethical and humanitarian values in our students. Around 40 faculty members of various departments have contributed so far to these sessions. Their innovative ideas, cooperation, sincere efforts, hard work and strong desire to inculcate ethical and humanitarian attitudes and a love for the art of medicine among the budding doctors of our institution, were phenomenal.

Evaluation of individual students remains the biggest challenge. Some experts have done only course-evaluation, based on the feedback given by the students (4). We too collected anonymous feedback in some of the individual sessions and at the end of each semester. However, assessment of individual behavioural change has not been possible. Difficulties in this regard have been emphasised by others also $(5,6,7,8)$. Wershof et al specifically mention that efforts have been made to quantify the impact of a Medical Humanities $(\mathrm{MH})$ course, however, subjective outcomes like increased empathy, professionalism and self-care are difficult to measure (6). Shankar PR, writing on the MH courses in India, wrote that measuring the long-term impact of $\mathrm{MH}$ is challenging and may be difficult. He has suggested that some pattern may be applied to small groups to gauge short term impact, but that it would be difficult and time consuming (7). Bleakley, in his chapter titled "Evaluating the impact of Medical Humanities provision" has discussed various challenges in the evaluation of attitudinal change (8: chap 9). In another article, he mentions that it may be akin to measuring the immeasurable (9). We, too, realised that evaluation is difficult but hope to evolve to some degree in this aspect as well, in the future.

An unintended yet important benefit, that accrued during the course of this programme, was the development of an increased spirit of camaraderie and cooperation among faculty across disciplines. We also believe that this programme has sparked in many members of the faculty, a deeper realisation of life, patient expectations and issues beyond the "traditional" curricular topics. This we think, will further enrich the fabric of our institute and society in the long term.

To conclude we have been able to successfully implement the HiM programme for the past three years. The major strengths of the programme were its formal integration within the curriculum and the contribution by a large number of enthusiastic, talented and motivated faculty. Though evaluation of behavioural and attitudinal change among individual students remains a challenge, we believe that this is a programme with benefits for all involved.

\section{Competing interests and funding support: None}

\section{References}

1. Oxford Living Dictionaries. [cited 2018 Jun 29] . Available from: https:// en.oxforddictionaries.com/definition/humanity

2. Kirklin D. The Centre for Medical Humanities, Royal Free and University College Medical School, London, England. Acad Med. 2003 Oct; 78(10): 1048- 53.

3. Medical Council of India. Attitude and Communication (AT-COM) Competencies for the Indian Medical Graduate. New Delhi: MCl, July 2015.

4. Abdel Halim RE, Alkattan KM. Introducing medical humanities in the medical curriculum in Saudi Arabia; a pedagogical experiment. Urol Ann. 2012 May-Aug; 4 (2) : 73- 9.

5. Downie R. Medical humanities: some uses and problems. JR Coll Physicians Edinb. 2016; 46(4) :288- 94.

6. Wershof SA, Abramson JS, Woinowich I, Accordino R, Ronan EJ, Rifkin MR.. Evaluating the impact of the humanities in medical education. $M t$ Sinai J Med. 2009 Aug; 76 (4) :372 -80.

7. Shankar PR. Medical humanities in medical schools in India. Arch Med Health Sci. 2016;4(2):166- 8.

8. Bleakley A.Medical humanities and medical education - How the medical humanities can shape better doctors. Routledge, London and New York. 2015

9. Bleakley A. Seven types of ambiguity in evaluating the impact of humanities provision in undergraduate medicine curricula. J Med Humanit. 2015;36:337-57. 